\title{
Enhancement of the power system distribution reliability using ant colony optimization and simulated annealing methods
}

\author{
Hadi Suyono $^{1}$, Rini Nur Hasanah ${ }^{2}$, Panca Mudjirahardjo ${ }^{3}$, M Fauzan Edy Purnomo ${ }^{4}$, Septi Uliyani ${ }^{5}$, \\ Ismail Musirin ${ }^{6}$, Lilik J. Awalin \\ $1,2,3,4,5$ Department of Electrical Engineering, Universitas Brawijaya (UB), Indonesia \\ ${ }^{6}$ Faculty of Electrical Engineering, Universiti Teknologi MARA (UiTM), Malaysia \\ ${ }^{7}$ Universiti Kuala Lumpur, British Malaysian Institute, Malaysia
}

\section{Article Info}

Article history:

Received May 28, 2019

Revised Jul 30, 2019

Accepted Aug 13, 2019

\section{Keywords:}

Ant colony optimization Power distribution reliability Reactive power compensation Relocation

Sectionalizer

Simulated annealing method

\begin{abstract}
The increasing demand of electricity and number of distributed generations connected to power system greatly influence the level of power service reliability. This paper aims at improving the reliability in an electric power distribution system by optimizing the number and location of sectionalizers using the Ant Colony Optimization (ACO) and Simulated Annealing (SA) methods. Comparison of these two methods has been based on the reliability indices commonly used in distribution system: SAIFI, SAIDI, and CAIDI. A case study has been taken and simulated at a feeder of Pujon, a place in East Java province of Indonesia, to which some distributed generators were connected. Using the existing reliability indices condition as base reference, the addition of two distributed plants, which were micro hydro and wind turbine plants, has proven to lower the indices as much as $0.78 \%$ for SAIFI, $0.79 \%$ for SAIDI, and $2.32 \%$ for CAIDI. The optimal relocation of the existing 16 sectionalizers in the network proved to decrease further the reliability indices as much as $43.96 \%$ for SAIFI, $45.52 \%$ for SAIDI, and $2.8 \%$ for CAIDI, which means bringing to much better reliability condition. The implementation of the SA method on the considered data in general resulted in better reliability indices than using the ACO method.
\end{abstract}

Copyright $@ 2020$ Institute of Advanced Engineering and Science. All rights reserved.

\section{Corresponding Author:}

Hadi Suyono,

Department of Electrical Engineering, Faculty of Engineering,

Universitas Brawijaya,

Jalan MT. Haryono 167 Malang 65145 Indonesia.

Email: hadis@ub.ac.id

\section{INTRODUCTION}

Electricity demand continues to increase along with the increasing population and growing economy. Its fulfillment requires an electric power distribution system with a high level of service reliability to ensure the continuity of electricity distribution to consumers [1-3].

Construction of distributed power plants is an alternative measure to overcome the increasing demand for electricity. Distributed generation is a term to refer to a small-capacity electricity generation system located and to be consumed dispersedly. The connection of distributed plants has been known to increase the efficiency and reliability of power system [4-10].

The reliability of a distribution network can be measured using the System Average Interruption Duration Index (SAIDI), the System Average Interruption Frequency Index (SAIFI), and the Costumer Average Interruption Duration Index (CAIDI). The high number of SAIDI and SAIFI indicates the low level of reliability and service to customers. A reliability improvement of distribution network can be achieved through optimal number and location of sectionalizers [11-13]. The relocation of sectionalizers can be seen as an optimization problem to be solved using artificial intelligence methods $[14,15]$. In order to improve the 
reliability indices of the distribution networks considered in this paper, two artificial intelligence-based methods have been explored, which were the Ant Colony Optimization (ACO) and Simulated Annealing (SA) methods.

\section{RESEARCH METHOD}

The adopted method to achieve the research purpose was based on the simulation of the proposed optimization algorithms using the real data of the object under consideration, by taking into account some scenarios.

\subsection{Required Data}

The required data include the single-line diagram of the substation to which the considered Pujon feeder was connected, the length of each line connected to the Pujon feeder, the customers at each load point, the capacity of power transformer at the substation, the loading data of the power transformer, sectionalizers, and the power capacity of the connected distributed generations.

\subsection{Calculation of the Existing Grid Reliability Indices}

The calculation of reliability indices includes the frequency and duration of interruptions at each load point of the Pujon feeder system. The overall SAIFI and SAIDI values are obtained by summing all the reliability indices values at each load point (bus).

The reliability indices of SAIDI and SAIFI for each equipment can be calculated using (1) and (2).

$$
\begin{aligned}
& S A I F I=\frac{\sum N_{T B} \times \lambda_{T B}}{\sum N} \\
& S A I D I=\frac{\sum N_{T B} x U_{T B}}{\sum N}=\frac{\sum \lambda_{i} x r_{j}}{\sum N}
\end{aligned}
$$

Using (1) and (2), the CAIDI can be obtained using (3).

$$
\text { CAIDI }=\frac{\text { sum of all customer interruption durations }}{\text { total number of customer interruptions }}=\frac{\text { SAIDI }}{\text { SAIFI }}
$$

\subsection{Calculation of Reliability Indices with Connected Distributed Generations}

The calculation process of the reliability indices after the introduction of distributed generators into the system follows the similar procedure of that for the existing conditions, except that three scenarios had been considered. The first scenario was the addition of wind turbine into the grid, the second case was the connection of micro hydro power plant to the grid, whereas in the third scenario both the wind turbine and micro hydro power plants were connected to the grid.

\subsection{Relocation of Sectionalizers After the Connection of Distributed Generations}

The attempts to optimize the placement and different numbers of sectionalizers as well as the calculation of the related reliability indices were to perform and compare using the ACO and SA methods.

\subsection{Analysis of Reliability Index using Ant Colony Optimization (ACO) Method}

The analysis using the ACO method starts with the determination of the ACO parameters. The change in the reliability index as well as the sectionalizer placement is influenced by the used parameters of the ACO method. The initial parameters of ACO to be used are given in Table 1.

The convergence is to be achieved before the maximum iteration number is reached, which is 100 . Higher the iteration number, longer the computation process to take. The alpha value controls the size of pheromone. Bigger the alpha value, more difficult the optimum point to reach. The ants number parameter represents certain combination of sectionalizers position at each bus. Each ant passing through each sector represents the position of sectionalizers placement at each bus. High number of ants used indicates high number of best path choices, as each ant will try to find the best path during computation process [10]. The number of ants to be used is 40 , to create the good randomizing condition.

\subsection{Analysis of Reliability Index using Simulated Annealing (SA) Method}

The change in the reliability index as well as the sectionalizer placement depends on the used parameters of the SA method. The SA parameters used are given in Table 2. The final stop temperature represents the final temperature to reach during the annealing process. The min value of function describes 
the minimum value as the targeted solution representing the achievement of the optimum fitness value, giving the minimum values of SAIDI and SAIFI. The cooling factor corresponds to the rate of temperature decrease, and has been set at 0.95 to produce slow cooling process and high number of iterations for convergence. The fitness function used during the optimization process is given in (4) [16-24].

$$
\text { fitness }=\frac{1}{S A I F I * S A I D I}
$$

Table 1. Parameters used in Optimization using ACO

\begin{tabular}{cc} 
Method & \\
\hline Parameters & Value \\
\hline Maximum iteration number & 100 \\
The ant number & 40 \\
Alpha & 1 \\
\hline
\end{tabular}

Table 2. Parameters used in Optimization using SA

\begin{tabular}{cc}
\multicolumn{2}{c}{ Method } \\
\hline Parameters & Value \\
\hline Final stop temperature & $1 e^{-20}$ \\
Min value of function & $1 e^{-10}$ \\
Max number of rejections & 100 \\
Max number of runs & 300 \\
Max number of accept & 10 \\
Boltzmann constant & 1 (default) \\
Cooling factor & 0.95 \\
\hline
\end{tabular}

\section{RESULTS AND ANALYSIS}

The data used in calculation and simulation, as well as the results of simulation for various scenarios are given as follows.

\subsection{Data of the Pujon Feeder at Sengkaling Substation}

The system considered in this paper is the Pujon feeder of Sengkaling substation, located in East Java province of Indonesia. The Sengkaling substation is supplied from another Kebonagung substation and operating at the receiving voltage of $150 \mathrm{kV}$. The Pujon feeder is operating at a medium voltage of $20 \mathrm{kV}$ and is supplied using the Transformer Three at the Sengkaling substation. The Pujon feeder has 8 sectionalizers located on bus 2 , bus 8 , bus 16 , bus 40 , bus 45 , bus 69 , bus 72 , and bus 102 . The calculation of reliability indices has been based on the data of the failure rate, duration of interruption and the transfer time of each distribution equipment. Those data referring to the Indonesian National Electricity Company Standard SPLN No. 59 (1985) concerning the reliability of $6 \mathrm{kV}$ and $20 \mathrm{kV}$ distribution systems which generally are applicable throughout Indonesia [13], are shown in Table 3.

Table 3. Data of the Failure Rate, Duration of Interruption and the Transfer Time of

\begin{tabular}{cccc}
\multicolumn{3}{c}{ Each Distribution Equipment } \\
\hline No. & Components & Failure rate (failure number/year) & Duration of interruption (hours) \\
\hline 1 & Overhead lines & $0.2 \mathrm{~km}$ & 3 \\
3 & Disconnecting switch & 0.004 & 10 \\
4 & Load switch & 0.003 & 10 \\
5 & Sectionalizer & 0.003 & 10 \\
6 & Cable connector & 0.001 & 15 \\
7 & Distribution transformer & 0.005 & 10 \\
9 & Low voltage rail & 0.001 & 10 \\
10 & Recloser & 0.005 & 10 \\
\hline
\end{tabular}

Load point, number of customers, the list of all lines, and line length of each part of the area have been analyzed to model the failure modes in the form of disturbances which occurred in each equipment of each area. The next step was the calculation of the frequency and duration of the interruption at each load point based on SPLN No.59 (1985). The reliability indices of SAIDI and SAIFI for each equipment were then calculated using (1) and (2). Using (1) and (2), the CAIDI could be obtained using (3).

\subsection{Power Capacity of Distributed Generations}

The distributed generations considered in this research were the micro hydro plant in Bendosari village and the wind turbine whose specifications are given in Table 4 and Table 5 [25]. 
Table 4. Specification of Micro Hydro Power Plant under Consideration

\begin{tabular}{cl}
\hline Parameters & \multicolumn{1}{c}{ Value } \\
\hline Output power & 8700 watts \\
Apparent Power (S) & $9666.66 \mathrm{VA}$ \\
Reactive Power (Q) & $4204.99 \mathrm{VAR}$ \\
Failure rate & 0.032 time/year \\
Interruption duration & 200 hours/year \\
\hline
\end{tabular}

Table 5. Specification of Wind Turbine under

\begin{tabular}{cl}
\multicolumn{2}{c}{ Consideration } \\
\hline Parameters & \multicolumn{1}{c}{ Value } \\
\hline Wind generated power/ & 36380.04 watt \\
Generator input power & 34561.04 watt \\
Output power & $36380.04 \mathrm{VA}$ \\
Apparent Power (S) & $11350.57 \mathrm{VAR}$ \\
Reactive Power (Q) & 0.02 time/year \\
Failure rate & 50 hours/year \\
Interruption duration
\end{tabular}

\subsection{Calculation results of the Existing Grid Reliability Indices}

Using the load point method, the reliability indices SAIFI and SAIDI have been calculated based on the failure rate and duration of interruption at each load point. The summation of all indices values at each load point would result in the total SAIFI and SAIDI values of the system. The calculation at each bus has been based on (5)-(7).

$$
\begin{aligned}
& f_{(i)}=S_{(i)} \& U_{(i)} \\
& S_{(i)}=\left(\lambda_{(\text {SUTM })} \times \text { linelength }_{(i)}+\lambda_{(\text {Trafo })}+S_{(1-n)}\right) \\
& U_{(i)}=\left(\lambda_{(\text {SUTM })} \times \text { linelength }_{(i)} \times r_{(\text {SUTM })}+\lambda_{(\text {Trafo })} \times r_{(\text {Trafo })}+U_{(1-n)}\right)
\end{aligned}
$$

In this step, there had not been any change in the sectionalizer placement and no connection of distributed generation. The calculation results are given in Table 6.

Table 6. The Reliability Indices of Existing Grid

\begin{tabular}{cccc}
\hline Condition & SAIFI (interruptions/year) & SAIDI (hours/year) & CAIDI (hours/year) \\
\hline Existing & 7.1697 & 22.2411 & 3.1021 \\
\hline
\end{tabular}

As indicated, without any change in the sectionalizers placement as well as with no distributed generation connection, boteh the indices SAIFI and SAIDI of the Pujon feeder did not fulfill the standard of SPLN68-2:1986, which were 3.2 interruptions/year for SAIFI and 21 hours/year for SAIDI. It is reasonable that sectionalizers had been installed to lower the SAIFI and SAIDI values at Pujon feeder.

\subsection{Calculation Results of the Reliability Indices with Connected Distributed Generations}

The calculation of the reliability indices has been carried out on three considered scenarios: grid wind turbine, grid - micro hydro plant, and grid - micro hydro plant - wind turbine. For the case of grid-wind turbine, the wind power plant has been injected on bus 117 with the load point of transformer 64. For the condition of grid-micro hydro plant, the distributed generation has been connected on bus 57 with the load point of transformer 32. The third case has been considered with both the connections of distributed generations on bus 117 and bus 57. The calculation results are presented in Table 7.

Table 7. The Reliability Indices of Existing Grid with Connected Distributed Generations

\begin{tabular}{cccc}
\hline Condition & SAIFI (interruptions/year) & SAIDI (hours/year) & CAIDI (hours/year) \\
\hline Grid-wind turbine & 7.0788 & 21.9508 & 3.0387 \\
Grid-micro hydro plant & 7.1321 & 22.1228 & 3.0389 \\
Grid-micro hydro plant-wind turbine & 7.1154 & 22.0657 & 3.0310 \\
\hline
\end{tabular}

Table 7 shows that the best improvement of reliability condition would be obtained with the injection of wind turbine power plant into the existing grid. This remark has been supported with the lowest indices of SAIFI and SAIDI, which are 7.0788 interruptions/year and 21.9508 hours/year respectively. 


\subsection{Comparison of the Reliability Condition Before and After the Connection of Distributed Generations}

Comparison analysis has been performed to examine the improvement of the reliability condition achieved after the addition of distributed generations. The improvement has been represented by the reduction of the indices SAIFI and SAIDI at the Pujon feeder, as seen in Table 8.

Table 8. The Reduction of Reliability Indices Achieved After the Connection of Distributed Generations

\begin{tabular}{cccc}
\hline \multirow{2}{*}{ Condition } & \multicolumn{3}{c}{ Index Reduction (\%) } \\
& SAIFI & SAIDI & CAIDI \\
\hline Existing & - & - & - \\
Grid-wind turbine & 1.26784 & 1.305241 & 2.043777 \\
Grid-micro hydro plant & 0.524429 & 0.531898 & 2.03733 \\
Grid-micro hydro plant-wind turbine & 0.7573 & 0.78863 & 2.291996 \\
\hline
\end{tabular}

\subsection{Results of Reliability Index using ant Colony Optimization (ACO) Method}

Based on the ACO parameters given in Table 1, the optimization process of sectionalizer relocation in the grid with the addition of distributed generations has been carried out using two variations of evaporation rate (rho), which were 0.1 and 0.3 . These variations have been implemented three times by varying the number of sectionalizers. The computation has been performed on all the three considered scenarios of distributed generations connection, which were the grid - wind turbine, grid - micro hydro plant, and grid - micro hydro plant - wind turbine cases.

The computation results of reliability indices using rho of 0.1 is presented in Table 9 by considering 16 sectionalizers. The computation evolutions of SAIFI and SAIDI for the condition case giving the best reliability are given in Figure 1a) and 1b) respectively with rho of 0.1 .

Table 9. The Best Reliability Indices After the Sectionalizer Optimization using ACO method with rho 0.1

\begin{tabular}{cccc}
\hline Condition & SAIFI (interruptions/ year) & SAIDI (hours/year) & \multicolumn{1}{c}{ Sectionalizer Location } \\
\hline Grid-wind turbine & \multirow{2}{*}{4.0136} & 12.071 & $\begin{array}{l}3,7,8,9,12,33,34,35,40, \\
42,43,77,78,82,89\end{array}$ \\
Grid-micro hydro plant & \multirow{2}{*}{4.0196} & 12.102 & $\begin{array}{l}3,7,9,12,33,34,35,40,42, \\
43,44,77,78,80\end{array}$ \\
$\begin{array}{c}\text { Grid-micro hydro plant-wind } \\
\text { turbine }\end{array}$ & \multirow{2}{*}{4.0093} & 12.0887 & $\begin{array}{l}3,7,8,9,12,34,41,42,57, \\
68,76,77,78,79,82,96\end{array}$ \\
\hline
\end{tabular}

As seen in Table 9 and Figure 1, the obtained values are varying as the optimization process using the ACO algorithm generates random numbers, even though relatively same relocation positions are produced. It is indicated from each condition that the increasing number of sectionalizer influences the reliability index of Pujon feeder. However, as shown, the change in the SAIFI, SAIDI, and CAIDI indices was insignificant. The highest reliability indices have been found under the condition case of grid-micro hydro plant-wind turbine with rho 0.1 , giving the SAIFI of 4.0093 interruptions/year and SAIDI of 12.0887 hours/year.

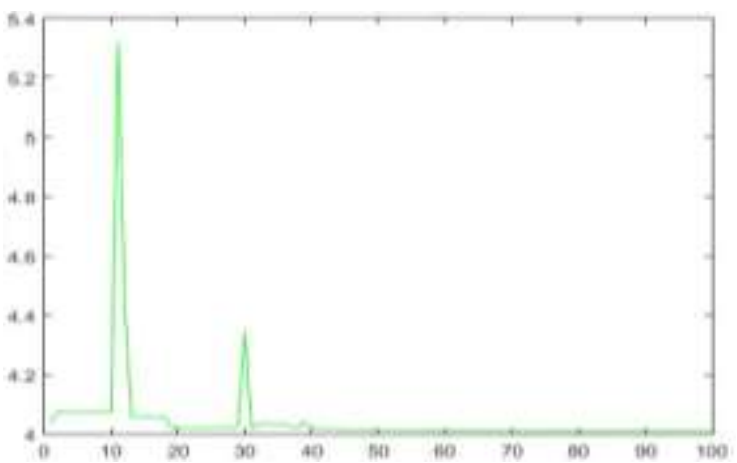

(a)

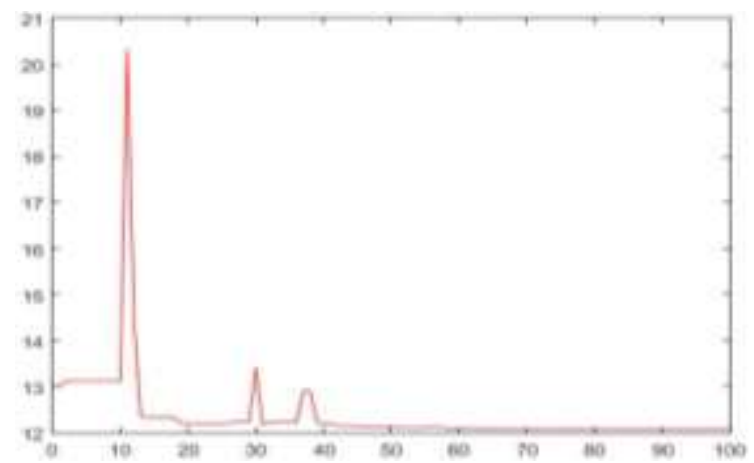

(b)

Figure 1. The best a) SAIFI, and b) SAIDI under the condition case of grid-micro hydro plant-wind turbine with rho 0.1 


\subsection{Results of Reliability Index using Simulated Annealing (SA) Method}

Based on the SA parameters given in Table 2, the process of sectionalizer relocation has been carried out using two variations of energy norm (enorm) [26], which were $1^{\mathrm{e}-2}$ and $1^{\mathrm{e}-3}$, representing the generated energy. These variations have been implemented three times by varying the number of sectionalizers. The computation has been performed on all the three considered scenarios of distributed generations connection, which were the grid - wind turbine, grid - micro hydro plant, and grid - micro hydro plant - wind turbine cases.

The computation results of reliability indices using enorm of $1^{\mathrm{e}-2}$ is presented in Table 10, by considering 16 sectionalizers. The computation evolutions of SAIFI and SAIDI for the condition case giving the best reliability are given in Figure $2 \mathrm{a}$ ) and $2 \mathrm{~b}$ ) with enorm $1^{\mathrm{e}-2}$.

Table 10. The Best Reliability Indices After the Sectionalizer Optimization using SA Method with enorm $1^{\mathrm{e}-2}$

\begin{tabular}{|c|c|c|c|}
\hline Condition & SAIFI (interruptions/ year) & SAIDI (hours/year) & Sectionalizer Location \\
\hline Grid-wind turbine & 4.0264 & 12.2085 & $\begin{array}{l}2,9,13,14,21,41,42,33,35 \\
55,6674,77,83,108,118\end{array}$ \\
\hline Grid-micro hydro plant & 4.0265 & 12.2216 & $\begin{array}{l}9,14,21,34,36,57,61,62,69, \\
79,81,87,88,90,116,118\end{array}$ \\
\hline $\begin{array}{l}\text { Grid-micro hydro plant-wind } \\
\text { turbine }\end{array}$ & 4.0185 & 12.1804 & $\begin{array}{l}3,8,9,16,27,42,44,47,47 \\
68,68,78,88,89,90,118\end{array}$ \\
\hline
\end{tabular}

As seen in Table 10, the obtained values are varying as the optimization using the SA algorithm generates random numbers. The number of sectionalizers influences the reliability index of Pujon feeder, but, as shown the change in the SAIFI, SAIDI, and CAIDI indices was insignificant. The highest reliability indices have been found under the condition case of grid-micro hydro plant-wind turbine with enorm $1^{\mathrm{e}-3}$, giving the SAIFI of 4.0224 interruptions/year and SAIDI of 12.219 hours/year.

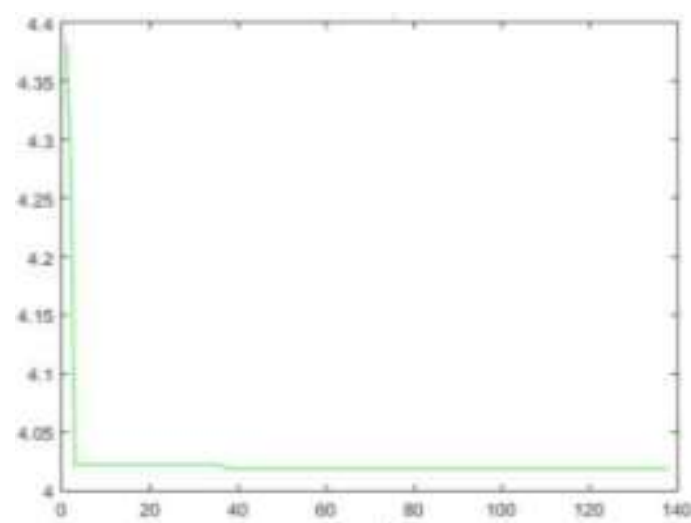

(a)

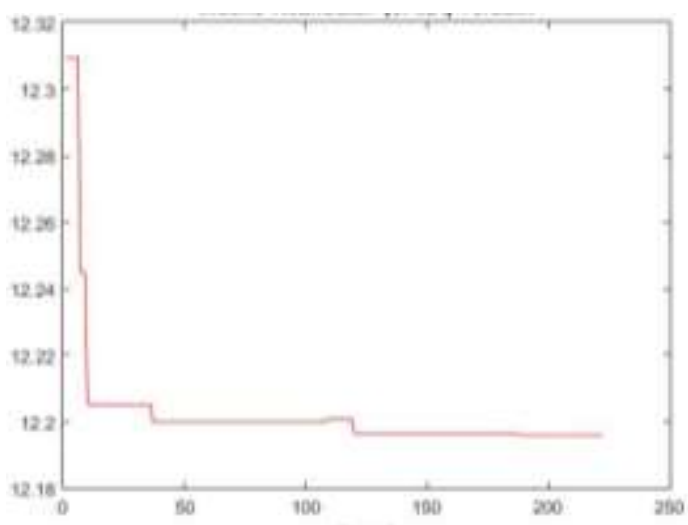

(b)

Figure 2. The best a) SAIFI, and b) SAIDI under the condition case of grid-micro hydro plant-wind turbine with enorm $1^{\mathrm{e}-2}$

\subsection{Comparison of Sectionalizer Optimization using ACO and SA Methods}

The best reliability condition has been achieved using the amount of sectionalizers of 16 , with the rho parameter of 0.1 using the Ant Colony Optimization method, and the enorm parameter of $1^{\mathrm{e}-3}$ using the Simulated Annealing method. In order to re-confirm the results, the implementation of the methods has been repeated 10 times using the parameters giving the previously best condition on the condition cases considered. The results are presented in Table 11, Table 12 and Table 13.

Comparing Table 11, Table 12 and Table 13 indicates that optimization using the ACO method produces the better reliability condition than using the SA method. Among the ten trials for each combination of grid with distributed generations, the best reliability indices of SAIFI, SAIDI, CAIDI on the scenario of grid-wind turbine using the ACO method were respectively 4.0138 interruptions/year, 12.073 hours/year, and 3.007873 hours/year, while using the SA method were 4.0247 interruptions/year, 12.1821 hours/year, and 3.026834 hours/year, respectively. 
Table 11. The Comparison Results of ACO and SA Methods on the Condition Case of Grid-Wind Turbine

\begin{tabular}{ccccccc}
\hline & \multicolumn{2}{c}{ Simulated Annealing (SA) method } & \multicolumn{2}{c}{ Ant Colony Optimization (ACO) method } \\
Trial & $\begin{array}{c}\text { SAIFI } \\
\text { (interruption/year) }\end{array}$ & $\begin{array}{c}\text { SAIDI } \\
\text { (hours/year) }\end{array}$ & $\begin{array}{c}\text { CAIDI } \\
\text { (hours/year) }\end{array}$ & $\begin{array}{c}\text { Best SAIFI } \\
\text { (interruption/year) }\end{array}$ & $\begin{array}{c}\text { Best SAIDI } \\
\text { (hours/year) }\end{array}$ & CAIDI \\
(hours/year)
\end{tabular}

Table 12. The Comparison Results of ACO and SA Methods on the Condition Case of Grid-Micro Hydro Plant

\begin{tabular}{|c|c|c|c|c|c|c|}
\hline \multirow[b]{2}{*}{ Trial } & \multicolumn{3}{|c|}{ Simulated Annealing (SA) method } & \multicolumn{3}{|c|}{ Ant Colony Optimization (ACO) method } \\
\hline & $\begin{array}{c}\text { SAIFI } \\
\text { (interruption/year) }\end{array}$ & $\begin{array}{c}\text { SAIDI } \\
\text { (hours/year) }\end{array}$ & $\begin{array}{c}\text { CAIDI } \\
\text { (hours/year) }\end{array}$ & $\begin{array}{c}\text { Best SAIFI } \\
\text { (interruption/year) }\end{array}$ & $\begin{array}{l}\text { Best SAIDI } \\
\text { (hours/year) }\end{array}$ & $\begin{array}{c}\text { CAIDI } \\
\text { (hours/year) }\end{array}$ \\
\hline 1 & 4.0338 & 12.2444 & 3.0355 & 4.0205 & 12.1112 & 3.01236 \\
\hline 2 & 4.0342 & 12.248 & 3.03604 & 4.0214 & 12.1201 & 3.01390 \\
\hline 3 & 4.032 & 12.2264 & 3.03234 & 4.0216 & 12.1226 & 3.01437 \\
\hline 4 & 4.0351 & 12.2579 & 3.03782 & 4.0217 & 12.1236 & 3.01455 \\
\hline 5 & 4.0383 & 12.2894 & 3.04321 & 4.0214 & 12.1199 & 3.01385 \\
\hline 6 & 4.0349 & 12.2557 & 3.03742 & 4.021 & 12.1166 & 3.01333 \\
\hline 7 & 4.0316 & 12.2227 & 3.03172 & 4.0206 & 12.1119 & 3.01246 \\
\hline 8 & 4.0349 & 12.2554 & 3.03735 & 4.0202 & 12.1085 & 3.01192 \\
\hline 9 & 4.0342 & 12.248 & 3.03604 & 4.0194 & 12.1002 & 3.01045 \\
\hline 10 & 4.0317 & 12.2236 & 3.03187 & 4.0209 & 12.1158 & 3.01321 \\
\hline
\end{tabular}

Table 13. The Comparison Results of ACO and SA Methods on the Condition Case of Grid-Wind Turbine-Micro Hydro Plant

\begin{tabular}{ccccccc}
\hline & \multicolumn{2}{c}{ Simulated Annealing (SA) method } & \multicolumn{2}{c}{ Ant Colony Optimization (ACO) method } \\
Trial & $\begin{array}{c}\text { SAIFI } \\
\text { (interruption/year) }\end{array}$ & $\begin{array}{c}\text { SAIDI } \\
\text { (hours/year) }\end{array}$ & $\begin{array}{c}\text { CAIDI } \\
\text { (hours/year) }\end{array}$ & $\begin{array}{c}\text { Best SAIFI } \\
\text { (interruption/year) }\end{array}$ & $\begin{array}{c}\text { Best SAIDI } \\
\text { (hours/year) }\end{array}$ & $\begin{array}{c}\text { CAIDI } \\
\text { (hours/year) }\end{array}$ \\
\hline 1 & 4.0243 & 12.2383 & 3.0411 & 4.0076 & 12.071 & 3.01203 \\
2 & 4.0219 & 12.214 & 3.03687 & 4.0088 & 12.0838 & 3.01432 \\
3 & 4.022 & 12.2151 & 3.03707 & 4.0082 & 12.0071 & 2.99563 \\
4 & 4.0208 & 12.2034 & 3.03507 & 4.0097 & 12.0927 & 3.01586 \\
5 & 4.0261 & 12.256 & 3.04414 & 4.0082 & 12.0778 & 3.01327 \\
6 & 4.0217 & 12.2123 & 3.03660 & 4.0085 & 12.0802 & 3.01365 \\
7 & 4.0227 & 12.2215 & 3.03813 & 4.0093 & 12.0879 & 3.01497 \\
8 & 4.0237 & 12.2321 & 3.04001 & 4.0096 & 12.0913 & 3.01559 \\
9 & 4.0232 & 12.2272 & 3.03917 & 4.0093 & 12.088 & 3.01499 \\
10 & 4.0206 & 12.2016 & 3.03477 & 4.0103 & 12.0987 & 3.01691 \\
\hline
\end{tabular}

On the scenario of grid-micro hydro plant, the ACO method resulted in the indices of respectively 4.0194 interruptions/year, 121002 hours/year, and 3.010449 hours/year, while using the SA method the indices were 4.0316 interruptions/year, 12.2227 hours/year, and 3.031724 hours/year, respectively. The related reliability indices on the scenario grid-wind turbine-micro hydro plant using the ACO method were respectively 4.0076 interruptions/year, 12.071 hours/year, and 3.012027 hours/year, while using the SA method were 4.0206 interruptions/year, 12.2016 hours/year, and 3.034771 hours/year, respectively. By observing the computation evolution curves, it can be known that the better results using the ACO method have been indicated by the better reliability indices and the relatively similar results of bus location on each computation trial. However, another remark concerning computation time should also be considered. The ACO method implementation required much longer time than the SA method. As an example, in one certain trial the ACO computation lasted \pm 173 seconds, whereas the SA method needed just \pm 13 seconds. 


\section{CONCLUSION}

Provide a statement that what is expected, as stated in the "Introduction" chapter can ultimately result in "Results and Discussion" chapter, so there is compatibility. Moreover, it can also be added the prospect of the development of research results and application prospects of further studies into the next (based on result Based on the results and analyses in this paper it can be concluded that the reliability of a distribution network could be improved by the addition of distributed generations into the network. In a case of network being equipped with sectionalizers, the reliability could still be improved further by optimally choosing the number and placement location of the sectionalizers. Comparing the use of two artificial intelligence-based optimization methods of the ACO and the SA methods, the previous one provided the better results but with much longer computation time. The perspectives of adding more and other types of distributed generations like solar photovoltaic plant, varying the number of sectionalizers, as well as using the combination of some artificial intelligence-based optimization methods are worth to consider.

\section{ACKNOWLEDGEMENTS}

The authors would like to thank the Board of Research and Community Service Activities of the Faculty of Engineering, Universitas Brawijaya, Indonesia for the funding of the research, the results of which are published in this publication, and to the Power System Engineering and Energy Management Research Group (PSeemRG) of Universitas Brawijaya, Indonesia, for facilitating the dissemination of this research result.

\section{REFERENCES}

[1] K. Jennett, et al., "Analysis of the sympathetic tripping problem for networks with high penetrations of Distributed Generation," in Proc. 2011 International Conference on Advanced Power System Automation and Protection, vol. 1, pp. 384-389, 2011.

[2] H. Suyono, et al., "Power system optimization of Static VAR Compensator using Novel Global Harmony Search Method," International Journal of Electrical and Electronic Engineering \& Telecommunications (IJEEET), vol. 8(1), pp. 26-32, 2019.

[3] K. Ma, et al., "Energy management considering unknown dynamics based on Extremum Seeking Control and Particle Swarm Optimization," IEEE Transactions on Control Systems Technology (Early Access), 2019.

[4] W. Chae, et al., "Optimal interconnection device for distributed energy resources of customer," in Proceedings of 2012 3rd IEEE International Symposium on Power Electronics for Distributed Generation Systems (PEDG), pp. 878-882, 2012.

[5] W.L. Ming and L. Jun, "Study on loss allocation of power distribution network with distributed generation," in Proceedings of The 2nd International Symposium on Power Electronics for Distributed Generation Systems, pp. 678-680, 2010.

[6] M.N. Hidayat and F. Li, "Impact of Distributed Generation technologies on generation curtailment," in 2013 IEEE Power \& Energy Society General Meeting, pp. 1-5, 2013.

[7] Z. Jun-fang, et al., "Research on distributed generation source placement," in Proceedings of 2009 International Conference on Sustainable Power Generation and Supply, pp. 1-4, 2009.

[8] W. Jian and C. Dongying, "Distributed control of power generation system," in Proceedings of 2012 International Conference on Computer Distributed Control and Intelligent Environmental Monitoring, pp. 253-256, 2012.

[9] G. Chen, et al., "Distributed optimal active power control of multiple generation systems," IEEE Transactions on Industrial Electronics, vol. 62(11), pp. 7079-7090, 2015.

[10] K.I. Jennett, et al., "Investigation of the sympathetic tripping problem in power systems with large penetrations of distributed generation," IET Generation, Transmission and Distributionvol. 9(4), pp. 379-385, 2015.

[11] M. Lwin, et al., "Protective device and switch allocation for reliability optimization with distributed generators," IEEE Transactions on Sustainable Energy, vol. 10(1), pp. 449-458, 2019.

[12] H. Ghoreishi, "Optimal placement of tie points and sectionalizers in radial distribution network in presence of DGs considering load significance," in Proceedings of 2013 Smart Grid Conference (SGC), pp. 160-165, 2013.

[13] PT. PLN (Indonesian National Electricity Company). SPLN 59: Reliability of 20kV and 6kV Distribution System. Jakarta: Ministry of Mines and Energy, 1985.

[14] M.K.M. Zamani, et al., "Optimal SVC allocation via symbiotic organisms search for voltage security improvement," TELKOMNIKA (Telecommunication, Computing, Electronics and Control), vol. 17(3), pp.1267-1274, 2019.

[15] H. Suyono, et al., "Optimization of the thyristor controlled phase shifting transformer using PSO algorithm," International Journal of Electrical and Computer Engineering (IJECE), vol. 8(6), pp. 5472-5483, 2018.

[16] F.M. Alhaddad and M.El-Hawary, "Optimal Filter Placement and Sizing Using Ant Colony Optimization in Electrical Distribution System," in Proceeding 2014 IEEE Electrical Power and Energy Conference, pp. 128-133, 2014.

[17] M. Gen, et al., "Network Models and Optimization: Multiobjective Genetic Algorithm Approach". New York: Springer-Verlag, 2008. 
[18] R. Jangra and R. Ramesh Kait, "Analysis and comparison among Ant System; Ant Colony System and Max-Min Ant System with different parameters setting," in Proceedings of 2017 3rd International Conference on Computational Intelligence \& Communication Technology (CICT), pp. 1-4, 2017.

[19] G. Ping, et al., "Adaptive ant colony optimization algorithm," in Proceedings of 2014 International Conference on Mechatronics and Control (ICMC), pp. 95-98, 2014

[20] R.A. ZeinEldin., "An improved simulated annealing approach for solving the constrained optimization problems," in Proceedings of 2012 8th International Conference on Informatics and Systems (INFOS), pp. BIO-27-BIO-31, 2012.

[21] Z. Shan, et al., "Reactive power optimization of distribution network based on GA with simulated annealing selection," in Proceedings of 2011 6th International Conference on Computer Science \& Education (ICCSE), pp. 1054-1057, 2011.

[22] J. Zhu, et al., "Simulated annealing ant colony algorithm for QAP," in Proceedings of 2012 8th International Conference on Natural Computation, pp. 789-793, 2012.

[23] T. Xin-Hua, et al., "A multi-objective Genetic Algorithm based on Simulated Annealing," in Proceedings of 2012 Fourth International Conference on Multimedia Information Networking and Security, pp. 413-416, 2012.

[24] P.C. Wang, et al., "A novel Differential Evolution algorithm based on simulated annealing," in Proceedings of 2010 Chinese Control and Decision Conference, pp. 7-10, 2010.

[25] H. Suyono, et al., "Power distribution system reliability improvement due to injection of distributed generation," in Proceedings of 2017 10th International Conference on Electrical and Electronics Engineering (ELECO), pp. 1485-1490, 2017.

[26] H.H. Örkcü., "Subset selection in multiple linear regression models: A hybrid of genetic and simulated annealing algorithms," Applied Mathematics and Computation, vol. 219(23), pp. 11018-11028, 1 Aug 2013. 